\title{
Cigarette acquisition and proof of age among US high school students who smoke
}

\author{
S Everett Jones, D J Sharp, C G Husten, L S Crossett
}

Tobacco Control 2002;11:20-25

See end of article for authors' affiliations

......................

Correspondence to: Dr Sherry Everett Jones,

Centers for Disease Control and Prevention, 4770 Buford Highway, NE, MS

K-33, Atlanta, GA 30341, USA; sce2@cdc.gov

Received 7 June 2001 and revision requested

20 August 2001 . Accepted

19 November 2001

\begin{abstract}
Objective: To determine how US high school students who are under 18 years of age and who smoke obtain their cigarettes and whether they are asked for proof of age.

Design and setting: Data from the Centers for Disease Control and Prevention's 1995, 1997, and 1999 national Youth Risk Behavior Surveys which employed national probability samples of students in grades 9-12 (ages 14-18 years).

Main outcome measures: Associations of usual source of cigarettes and request for proof of age with variables such as sex, race/ethnicity, grade, and frequency of smoking.

Results: In 1999, among current smokers under age 18 years, 23.5\% (95\% confidence interval (Cl), $-4.5 \%$ to $+4.5 \%$ ) usually purchased their cigarettes in a store; among these students, $69.6 \% 195 \% \mathrm{Cl}$ $-5.7 \%$ to $+5.7 \%$ ) were not asked to show proof of age. As days of past month smoking increased, reliance on buying cigarettes in a store $(p<0.001)$ and giving someone else money to buy cigarettes $(p<0.001)$ increased, and usually borrowing cigarettes decreased ( $p<0.001)$. From 1995 to 1999 , relying on store purchases significantly decreased (from $38.7 \%(95 \% \mathrm{Cl}-4.6 \%$ to $+4.6 \%$ ) to $23.5 \%$ $(95 \% \mathrm{Cl}-4.5 \%$ to $+4.5 \%))$; usually giving someone else money to buy cigarettes significantly increased (from $15.8 \%(95 \% \mathrm{Cl}-3.6 \%$ to $+3.6 \%)$ to $29.9 \%(95 \% \mathrm{Cl}-4.5 \%$ to $+4.5 \%)$ ).

Conclusions: Stricter enforcement of tobacco access laws is needed to support other community and school efforts to reduce tobacco use among youth. Furthermore, effective interventions to reduce noncommercial sources of tobacco, including social, need to be developed and implemented.
\end{abstract}

A mong adults who have ever smoked daily, more than $80 \%$ first smoked cigarettes before the age 18 years. ${ }^{1}$ Thousands of teenagers smoke their first cigarette and become daily smokers each day. ${ }^{2}$ The age at which smoking begins influences the total number of years of smoking, the number of cigarettes smoked per day in adulthood, and the likelihood of quitting. ${ }^{13-6}$ All of these factors affect the risk for developing smoking attributable disease and disability such as lung cancer and other fatal malignancies, atherosclerosis and coronary heart disease, and chronic obstructive pulmonary disease. ${ }^{17}$ The Centers for Disease Control and Prevention (CDC) has estimated that if current patterns of smoking behaviour continue, five million Americans aged $0-17$ years in 1995 could die prematurely from diseases related to smoking. ${ }^{8}$ Thus, preventing or delaying initiation is critical to preventing and reducing the morbidity and mortality associated with cigarette smoking. ${ }^{1}$

National health objectives set forth in "Healthy People $2010^{\prime \prime}$ seek to reduce tobacco use by adolescents and adults, ${ }^{9}$ and one of the 10 leading health indicators in that report focuses specifically on preventing tobacco use among adolescents. In addition, two national health objectives specifically focus on reducing sales to minors: objective 27-14 is to "reduce the illegal buy rate among minors through enforcement of laws prohibiting the sale of tobacco products to minors", and objective $27-15$ is to "increase the number of states and the District of Columbia that suspend or revoke state retail licenses for violations of laws prohibiting the sale of tobacco to minors". ${ }^{\prime}$

In 2000, the US Supreme Court held that the Food and Drug Administration did not have the authority to regulate tobacco products, including their marketing and availability. ${ }^{10}$ The Public Health Service Act 398 (the Synar Amendment), however, which was passed in 1992, makes block grants to states from the Substance Abuse and Mental Health Services Administration (SAMHSA) contingent on states enacting and enforcing laws prohibiting any manufacturer, retailer, or distributor from selling or distributing tobacco products to persons under age 18 years. ${ }^{11}{ }^{12}$ All 50 states currently have laws prohibiting the sale of tobacco to minors. ${ }^{12}$ Numerous studies since the late 1980s have demonstrated, however, that without adequate enforcement, minors are frequently successful in purchasing cigarettes from commercial sources when they try. ${ }^{13-17}$ In 1999, most 8 th and 10th grade students reported they could get cigarettes "fairly easily" or "very easily" (72\% and $88 \%$, respectively), ${ }^{18}$ and data from self report surveys confirm that many youth purchase their tobacco from commercial sources. ${ }^{19-23}$ To date, however, no published reports have focused on how the sources of cigarettes for youth have changed over time.

The purposes of this study were to examine: (1) how high school students under age 18 years (minors) who smoke usually obtain their cigarettes; (2) whether minors' frequency of smoking is associated with their source of cigarettes; (3) secular trends in usual source of cigarettes among minors from 1995 to 1999; and (4) whether minors are asked to show proof of age when they buy cigarettes in a store.

\section{METHODS \\ Study design}

This study used data from the 1995, 1997, and 1999 national school based Youth Risk Behavior Survey (YRBS), which has been conducted biennially by the CDC since 1991 (the first national YRBS was conducted in the spring of 1990). The questionnaires covered six categories of behaviours, including those that contribute to unintentional injuries and violence,

Abbreviations: CDC, Centers for Disease Control and Prevention; PSU, primary sampling unit; SAMHSA, Substance Abuse and Mental Health Services Administration; YRBS, Youth Risk Behavior Survey 
Table 1 Minors' usual source of cigarettes in 1999*

\begin{tabular}{|c|c|c|c|c|c|c|}
\hline & $\begin{array}{l}\text { Usually bought } \\
\text { in a store } \\
\%( \pm 95 \% \mathrm{Cl})\end{array}$ & $\begin{array}{l}\text { Usually bought in a } \\
\text { vending machine } \\
\%( \pm 95 \% \mathrm{Cl})\end{array}$ & $\begin{array}{l}\text { Usually gave someone } \\
\text { else money to buy } \\
\%( \pm 95 \% \mathrm{CI})\end{array}$ & $\begin{array}{l}\text { Usually borrowed } \\
\text { from someone } \\
\%( \pm 95 \% \mathrm{Cl})\end{array}$ & $\begin{array}{l}\text { Usually stole } \\
\% \text { ( } \pm 95 \% \mathrm{Cl})\end{array}$ & $\begin{array}{l}\text { Usually obtained in } \\
\text { some other way } \\
\%( \pm 95 \% \mathrm{Cl})\end{array}$ \\
\hline Total & $23.5(4.5)$ & $1.1(0.8)$ & $29.9(4.0)$ & $30.4(3.8)$ & $4.4(1.2)$ & $10.7(2.1)$ \\
\hline \multicolumn{7}{|l|}{ Sex } \\
\hline Female & $17.6(5.6)$ & $1.2(1.4)$ & $33.9(5.0)$ & $33.3(4.4)$ & 2.6 (1.0) & $11.4(3.8)$ \\
\hline Male & $29.8(4.7)$ & $0.9(0.5)$ & $25.6(5.1)$ & $27.4(4.8)$ & $6.4(2.2)$ & $10.0(2.8)$ \\
\hline \multicolumn{7}{|c|}{ Race/Ethnicity } \\
\hline White & $24.5(4.4)$ & $1.0(1.1)$ & $32.9(4.5)$ & $29.0(3.7)$ & $4.2(1.4)$ & 8.5 (1.7) \\
\hline Black & 30.7 (13.6) & $1.1(0.9)$ & $13.5(7.3)$ & $35.8(6.7)$ & $4.7(3.1)$ & 14.2 (11.2) \\
\hline Hispanic & $20.1(6.6)$ & $2.2(1.6)$ & $23.1(4.1)$ & $33.6(5.2)$ & $4.4(2.5)$ & $16.6(5.4)$ \\
\hline \multicolumn{7}{|l|}{ Grade } \\
\hline 9 th & $12.1(4.8)$ & $1.8(2.0)$ & $31.7(7.3)$ & $31.5(6.2)$ & $8.1(3.6)$ & $14.8(5.6)$ \\
\hline 10th & $21.9(7.5)$ & $0.5(0.6)$ & $34.1(6.8)$ & $30.5(4.1)$ & $2.3(1.1)$ & $10.6(4.0)$ \\
\hline 11 th & $28.5(6.4)$ & $0.8(0.8)$ & $27.0(6.7)$ & $29.8(7.1)$ & $4.1(2.0)$ & $9.9(2.9)$ \\
\hline 12 th & $38.7(7.0)$ & $0.8(0.8)$ & $23.3(8.2)$ & $30.7(7.1)$ & $1.8(1.3)$ & $4.7(6.5)$ \\
\hline
\end{tabular}

*Among high school students who were current smokers (smoked cigarettes on one or more of the 30 days preceding the survey) and under age 18 years (unweighted $n=3631$ ). Data are from the 1999 Youth Risk Behavior Survey.

$\mathrm{Cl}$, confidence intervals.

tobacco use, alcohol and other drug use, sexual behaviours that contribute to unintended pregnancies and sexually transmitted diseases, dietary behaviours, and physical activity. In 1995, the YRBS queried students about their usual source of cigarettes for the first time.

Each YRBS used a three stage, cluster sample design to obtain a nationally representative sample of students in grades 9 through 12 (ages $14-18$ years). ${ }^{21-23}$ The target population consisted of all public and private high school students in the 50 states and the District of Columbia. The first stage sampling frame contained primary sampling units (PSUs) made up of large counties or groups of smaller adjacent counties. From this frame, PSUs were selected from 16 strata formed according to the degree of urbanisation and the relative percentages of black and Hispanic students in the PSUs. The PSUs were selected with a probability of selection proportional to their total school enrolment.

In the second stage, schools were selected from the PSUs with a probability proportional to their school enrolment. To ensure that racial or ethnic subgroups were large enough to analyse subgroup differences, schools with substantial numbers of black and Hispanic students were sampled at relatively higher rates than were other schools. The final stage consisted of randomly selecting, within each chosen school and in each of the four grades, one or two entire classes of a required subject such as English or social studies. All students in the selected classes were eligible to participate.

Procedures were designed to protect the students' privacy by allowing for anonymous and voluntary participation and CDC's institutional review board granted clearance for the survey. Local parental permission procedures were followed before survey administration. A questionnaire containing approximately 90 items was administered in the classroom by trained data collectors. Answers were recorded directly on a computer scannable booklet. For 1995, 1997, and 1999, the school response rates were $70 \%, 79 \%$, and $77 \%$, respectively; student response rates were $86 \%, 87 \%$, and $86 \%$; overall response rates were $60 \%, 69 \%$, and $66 \%$; and sample sizes were 10904,16262 , and 15349 .

\section{Data analysis}

In each survey, smoking status was assessed by the question: "During the past 30 days, on how many days did you smoke cigarettes?" Response options ranged from "0 days" to "all 30 days". Students were defined as current smokers if they had smoked on one or more days. In each of the three surveys, usual source of cigarettes (both commercial and noncommercial, including social sources) was assessed by the question: "During the past 30 days, how did you usually get your own cigarettes?" Students could choose (only) one response from among the following: "I did not smoke cigarettes in the past 30 days", "I bought them in a store such as a convenience store, supermarket, or gas station", "I bought them from a vending machine", "I gave someone else money to buy them for me", "I borrowed them from someone else", "I stole them", or "I got them in some other way". Proof of age was assessed in 1999 only, using the question: "When you bought cigarettes in a store during the past 30 days, were you ever asked to show proof of age?" Responses included "I did not buy cigarettes in a store during the past 30 days", "Yes", and "No".

A weighting factor was applied to each student record to adjust for non-response and for the varying probabilities of selection, including those resulting from the oversampling of black and Hispanic students. The final, overall weights were scaled so that the weighted count of students equalled the total sample size, and the weighted proportions of students in each grade matched national population projections for each survey year. All estimates were based on weighted data. All analyses were subsetted among current smokers who were under age 18 (sample sizes were 2989 in 1995, 4108 in 1997, and 3631 in 1999). Racial/ethnic data are presented only for white, black, and Hispanic students because sample sizes in other minority groups were too small for meaningful analysis.

We used SUDAAN, ${ }^{24}$ a software package that takes into account the complex sampling design of this survey, to generate all point estimates and $95 \%$ confidence intervals (CIs), and to conduct all tests for significance ( $\alpha$ level was set at $\mathrm{p}<0.05)$. We used $\chi^{2}$ tests to assess main effects in students' usual source of cigarettes and being asked for proof of age by sex, race/ethnicity, and grade. When significant main effects were identified, we used $t$ tests to identify the racial/ethnic and grade differences in these variables. To examine the relation between the number of days of past month smoking and the usual source of cigarettes, a logistic regression model was used that controlled for sex, grade, and race/ethnicity, in which days of use was treated as a continuous variable.

To examine secular trends in students' usual source of cigarettes, we combined YRBS data from 1995, 1997, and 1999 because in those years, the wording about usual source of cigarettes was identical. In combining the data sets, we recoded the strata from each survey year so that strata from one survey year were uniquely identifiable and separate from those of other survey years, essentially creating an additional stratum of "time". In subsequent logistic regression models that controlled for sex, grade, and race/ethnicity, time was treated as a continuous variable in assessing possible linear changes in usual source of cigarettes. 
Table 2 Minors' usual source of cigarettes in 1999, by frequency of smoking*

\begin{tabular}{|c|c|c|c|c|c|c|}
\hline & $\begin{array}{l}\text { Usually bought } \\
\text { in a store } \\
\%( \pm 95 \% \mathrm{Cl})\end{array}$ & $\begin{array}{l}\text { Usually bought in a } \\
\text { vending machine } \\
\%( \pm 95 \% \mathrm{Cl})\end{array}$ & $\begin{array}{l}\text { Usually gave someone } \\
\text { else money to buy } \\
\%( \pm 95 \% \mathrm{Cl})\end{array}$ & $\begin{array}{l}\text { Usually borrowed } \\
\text { from someone } \\
\%( \pm 95 \% \mathrm{Cl})\end{array}$ & $\begin{array}{l}\text { Usually stole } \\
\% \text { ( } \pm 95 \% \mathrm{CI})\end{array}$ & $\begin{array}{l}\text { Usually obtained in } \\
\text { some other way } \\
\%( \pm 95 \% \mathrm{Cl})\end{array}$ \\
\hline \multicolumn{7}{|c|}{ Days smoked in past month } \\
\hline $1-2$ & $6.7(3.1)$ & $0.2(0.3)$ & $6.8(2.7)$ & $66.7(8.2)$ & 3.2 (2.7) & $16.5(5.7)$ \\
\hline $3-5$ & $11.1(5.5)$ & $0.2(0.3)$ & $14.0(5.5)$ & $60.6(7.8)$ & 6.4 (3.0) & $7.8(2.6)$ \\
\hline $6-9$ & 19.7 (12.3) & $2.9(2.0)$ & $26.6(9.1)$ & $39.3(10.4)$ & $5.6(4.0)$ & $5.8(3.8)$ \\
\hline 10-19 & $26.3(9.3)$ & $0.6(0.7)$ & $38.8(9.2)$ & $21.0(4.9)$ & $0.6(0.6)$ & $12.7(7.8)$ \\
\hline 20-29 & $31.4(10.3)$ & $1.3(1.4)$ & $50.8(8.4)$ & $9.1(4.0)$ & $4.6(4.2)$ & $2.8(1.7)$ \\
\hline All 30 & $36.8(8.2)$ & $1.3(1.7)$ & $42.0(7.7)$ & $3.3(1.6)$ & $5.5(2.0)$ & $11.1(3.1)$ \\
\hline Linear trend $(p) \dagger$ & $<0.001$ & NS & $<0.001$ & $<0.001$ & NS & NS \\
\hline
\end{tabular}

*Among high school students who were current smokers (smoked cigarettes on one or more of the 30 days preceding the survey) and were under age 18 years (unweighted $n=3631$ ). Data are from the 1999 Youth Risk Behavior Survey.

†Test for trend was calculated from a logistic regression model, controlling for sex, grade, and race/ethnicity, in which the independent variable (number of days of use) was treated as a continuous variable (NS, not significant).

\section{RESULTS}

\section{Minors' usual source of cigarettes}

Bought them in a store. Overall, in 1999, 23.5\% of current smokers usually got their cigarettes by buying them in a store (table 1). The percentage of students who usually got their cigarettes by buying them in a store varied by $\operatorname{sex}\left(\chi^{2}=21.8, d f=1\right.$, $\mathrm{p}<0.001)$ and by grade $\left(\chi^{2}=1.8, d f=3, \mathrm{p}<0.001\right)$. Males were significantly more likely than females and 12th grade students were significantly more likely than 9th $(t=6.8$, $\mathrm{p}<0.01)$, 10th $(t=5.0, \mathrm{p}<0.01)$, and 11th grade students $(t=2.6, \mathrm{p}=0.01)$ to buy their cigarettes in a store.

Bought them from a vending machine. Only $1.1 \%$ of current smokers usually got their cigarettes by buying them from a vending machine. This behaviour did not vary by sex, race/ethnicity, or grade.

Gave someone else money to buy them. Three of 10 (29.9\%) current smokers usually got their cigarettes by giving someone else money to buy them. The percentage of students who usually gave someone else money to buy their cigarettes varied by sex $\left(\chi^{2}=9.0, d f=1, \mathrm{p}<0.01\right)$ and by race/ethnicity $\left(\chi^{2}=16.4, d f=2, \mathrm{p}<0.001\right)$. Females were significantly more likely than males to give someone else money to buy their cigarettes. White students were significantly more likely to report this behaviour than were black $(t=4.2, \mathrm{p}<0.01)$ and Hispanic $(t=3.2, \mathrm{p}<0.01)$ students and Hispanic students were significantly more likely than black students to report this behavior $(t=2.3, \mathrm{p}<0.05)$.

Borrowed them from someone else. Overall, $30.4 \%$ of current smokers usually got their cigarettes by borrowing them. The percentage of students who usually borrowed their cigarettes from someone else varied by $\operatorname{sex}\left(\chi^{2}=4.5, d f=1, \mathrm{p}<0.05\right)$ and by race/ethnicity $\left(\chi^{2}=7.8, d f=2, \mathrm{p}<0.05\right)$. Significantly more females than males and significantly more black students than white students $(t=2.2, \mathrm{p}<0.05)$ borrowed cigarettes from someone else.

Stole them. Overall, $4.4 \%$ of current smokers usually stole their cigarettes. The percentage of students who usually stole their cigarettes varied by $\operatorname{sex}\left(\chi^{2}=10.1, d f=1, \mathrm{p}<0.01\right)$ and by grade $\left(\chi^{2}=12.6, d f=3, p<0.01\right)$. Males were significantly more likely than females to steal their cigarettes. Eleventh $(t=2.2, \mathrm{p}<0.05)$ and 9th grade students $(t=3.2, \mathrm{p}<0.01)$ were significantly more likely than 12 th grade students to report stealing their cigarettes. Ninth grade students were significantly more likely than 10th grade students to do so $(t=3.0, \mathrm{p}<0.01)$.

Got them in some other way. Overall, just over one in 10 $(10.7 \%)$ current smokers usually got their cigarettes in "some other way". The percentage of students who usually got their cigarettes in some other way varied by race $\left(\chi^{2}=8.1, d f=2\right.$, $\mathrm{p}<0.05)$. Hispanic students were significantly more likely than white students $(t=3.0, \mathrm{p}<0.01)$ to get their cigarettes in some other way.

\section{Frequency of smoking and minors usual source of cigarettes}

In 1999, the number of days students reported smoking was associated with the usual source of their cigarettes (table 2). As the number of days of smoking increased, the likelihood of students reporting buying their own cigarettes in a store $(p<0.01)$ and giving someone money to buy cigarettes $(\mathrm{p}<0.01)$ increased. In contrast, as the number of days of smoking increased, the less likely students were to borrow cigarettes $(p<0.01)$. Neither buying cigarettes from a vending machine nor stealing them was associated with frequency of smoking. Obtaining cigarettes in "some other way" did not demonstrate a linear pattern with smoking frequency, but students who smoked 1-2 days during the past month were significantly more likely than students who smoked 3-5 days $(t=3.2$, $\mathrm{p}<0.01), 6-9$ days $(t=2.8, \mathrm{p}<0.01)$, and 20-29 days $(t=4.5$, $\mathrm{p}<0.01$ ) to report getting their cigarettes in this other manner.

\section{Secular trends in minors' usual source of cigarettes}

The percentage of current smokers who reported they usually got their own cigarettes by buying them in a store significantly decreased from $38.7 \%$ in 1995 to $23.5 \%$ in 1999 (linear trend, $\mathrm{p}<0.001$ ) (table 3). Conversely, giving someone else money

Table 3 Secular trends in minors' usual source of cigarettes, 1995-1999*

\begin{tabular}{|c|c|c|c|c|c|c|}
\hline & $\begin{array}{l}\text { Usually bought } \\
\text { in a store } \\
\%( \pm 95 \% \mathrm{CI})\end{array}$ & $\begin{array}{l}\text { Usually bought in a } \\
\text { vending machine } \\
\%( \pm 95 \% \mathrm{Cl})\end{array}$ & $\begin{array}{l}\text { Usually gave someone } \\
\text { else money to buy } \\
\%( \pm 95 \% \mathrm{Cl})\end{array}$ & $\begin{array}{l}\text { Usually borrowed } \\
\text { from someone } \\
\%( \pm 95 \% \mathrm{Cl})\end{array}$ & $\begin{array}{l}\text { Usually stole } \\
\%( \pm 95 \% \mathrm{CI})\end{array}$ & $\begin{array}{l}\text { Usually obtained in } \\
\text { some other way } \\
\%( \pm 95 \% \mathrm{Cl})\end{array}$ \\
\hline \multicolumn{7}{|l|}{ Year } \\
\hline 1995 & $38.7(4.6)$ & $2.2(0.9)$ & $15.8(3.6)$ & $32.9(4.0)$ & $4.2(1.3)$ & 6.2 (1.7) \\
\hline 1997 & $29.8(4.8)$ & $1.7(0.7)$ & 22.9 (4.0) & $33.0(2.9)$ & $3.6(1.3)$ & 9.0 (1.9) \\
\hline 1999 & $23.5(4.5)$ & $1.1(0.8)$ & 29.9 (4.0) & $30.4(3.8)$ & $4.4(1.2)$ & $10.7(2.1)$ \\
\hline Linear trend $(p) \dagger$ & $<0.001$ & NS & $<0.001$ & NS & NS & 0.004 \\
\hline
\end{tabular}

*Among high school students who were current smokers (smoked cigarettes on one or more of the 30 days preceding the survey) and under age 18 years (unweighted n's $=2989$ in 1995; 4108 in 1997; 3631 in 1999). Data are from the 1995, 1997, and 1999 Youth Risk Behavior Survey.

†Test for trend was calculated from a logistic regression model, controlling for sex, grade, and race/ethnicity (NS, not significant). 
Table 4 Percentage of minors not asked for proof of age when buying cigarettes in a store in 1999*

\begin{tabular}{ll}
\hline & $\begin{array}{l}\text { Not asked to show proof of } \\
\text { age when buying in a store } \\
\%( \pm 95 \% \mathrm{CI})\end{array}$ \\
\hline $\begin{array}{l}\text { Total } \\
\text { Sex }\end{array}$ & $69.6(5.7)$ \\
Female & $76.2(7.9)$ \\
Male & $65.5(5.7)$ \\
Race/ethnicity & $65.7(7.5)$ \\
White & $84.1(13.0)$ \\
Black & $60.7(12.6)$ \\
Hispanic & $79.1(9.9)$ \\
Grade & $67.9(9.9)$ \\
9th & $68.4(13.1)$ \\
10th & $65.0(10.9)$ \\
11th & \\
12th &
\end{tabular}

* Among high school students who were current smokers (smoked cigarettes on one or more of the 30 days preceding the survey), under age 18 years, and bought cigarettes in a store or gas station during the 30 days preceding the survey (unweighted $n=3631$ ). All data are presented as percentages ( $\pm 95 \%$ confidence intervals). Data are from the 1999 Youth Risk Behavior Survey.

to buy cigarettes significantly increased from 1995 (15.8\%) to 1999 (29.9\%) (linear trend, p < 0.001). Obtaining cigarettes in "some other way" also significantly increased from $6.2 \%$ in 1995 to $10.7 \%$ in 1999 (linear trend, $\mathrm{p}=0.004$ ). Buying cigarettes in a vending machine, borrowing cigarettes from someone else, and stealing cigarettes remained stable from 1995 to 1999.

\section{Not asked proof of age when bought during past 30 days}

In 1999, among current smokers under age 18 years who bought cigarettes in a store during the 30 days preceding the survey, $69.6 \%$ were never asked to show proof of age (table 4 ).

The percentage of students who were not asked for proof of age varied by sex $\left(\chi^{2}=5.8, d f=1, \mathrm{p}<0.05\right)$. Females were significantly more likely than males to report they had not been asked to show proof of age. Requests for proof of age did not vary across race/ethnicity or grade.

\section{DISCUSSION}

In this study, from 1995 to 1999 we found a shift in cigarette acquisition from commercial sources to social sources among high school students. Among current smokers under age 18 years, the percentage of students who usually bought their own cigarettes in a store dropped from $38.7 \%$ in 1995 to $23.5 \%$ in 1999; students who reported that they usually gave someone else money to buy cigarettes significantly increased from $15.5 \%$ to $29.9 \%$.

Preventing minors' access to tobacco by prohibiting retail sales to them has been advocated to help reduce initiation of tobacco use and is recommended as a component of comprehensive tobacco control programmes. ${ }^{125-27}$ It is well established that active enforcement of state laws or local ordinances can reduce the percentage of retailers who sell tobacco to minors, ${ }^{1} 131425262829$ especially when compliance checks are performed several times per year. ${ }^{30-32}$ Likewise, education of merchants has been shown in some studies to be useful in decreasing the percentage of retailers who sell tobacco to minors, although such education without active enforcement loses effectiveness over time. ${ }^{1325}$

Some studies have shown that combining community mobilisation with enforcement of access laws, retailer education, school based education, or stronger local laws may reduce the prevalence of youth smoking, ${ }^{13}{ }^{33-35}$ but such findings are not universal. For example, in a Massachusetts study that combined retailer education and active enforcement, despite a

\section{What this paper adds}

All 50 states currently have laws prohibiting the sale of tobacco to minors. However, without adequate enforcement, minors are frequently successful in purchasing cigarettes when they try. Also, studies suggest social sources are an important means of cigarette acquisition.

Data from the 1999 national Youth Risk Behavior Survey showed that among high school students under age 18 who were current smokers, $23.5 \%$ usually purchased their own cigarettes in a store, $29.9 \%$ usually gave someone else money to buy their cigarettes, and $30.4 \%$ usually borrowed cigarettes from someone. From 1995 to 1999, usually buying cigarettes in a store significantly declined; however, usually giving someone else money to buy cigarettes significantly increased.

pronounced reduction in the percentage of retailers who sold cigarettes to youth in the intervention communities, there was no difference in self reported access by youth in intervention compared to control communities. ${ }^{14}$ The authors observed that unless youth in intervention communities report decreased access to commercial sources of cigarettes, and that decrease is greater than any decrease in access that may have occurred in the control communities, it is not logical to expect reduced cigarette use among youth in the intervention communities as a result of the intervention. ${ }^{1 .}$

The 1999 YRBS data suggest that many young smokers who purchased cigarettes in a store were not asked for proof of age. The YRBS does not provide data on the percentage of students who tried unsuccessfully to buy cigarettes. Data from other studies show that when store personnel request proof of age for a cigarette purchase, the likelihood of a sale to an underage buyer is greatly reduced. ${ }^{15303136}$ Thus, merchant education programmes to reduce sales of cigarettes to minors should emphasise the need to request proof of age.

Consistent with other studies, ${ }^{20}{ }^{37-41}$ YRBS data showed that social sources continue to be an important means of cigarette acquisition. For example, in 1999, YRBS data and National Youth Tobacco Survey ${ }^{20}$ data found that more than half of high school students usually obtained their cigarettes by either giving someone else money to buy them or borrowing them. The Tobacco Policy Options for Prevention study in Minnesota found that more than $90 \%$ of 8 th-10th graders who had ever smoked cigarettes obtained their first cigarette from family members or friends. ${ }^{37}$ Likewise, Wolfson and colleagues ${ }^{38}$ found that more than two thirds of students in these grades who reported past month smoking had provided tobacco to another student during that same period. Of those students, $66 \%$ provided tobacco to a same age friend, $37 \%$ to a younger friend, $17 \%$ to a sibling, and $13 \%$ to a stranger.

Wolfson and colleagues ${ }^{38}$ as well as others ${ }^{39}{ }^{40}$ have found that adolescents who are heavier smokers are the most likely to provide cigarettes to other adolescents; we found that heavier smokers were more likely to obtain their cigarettes by purchase. Thus, it is likely that the original source for a substantial percentage of cigarettes "borrowed" from other minors was from an illegal sale at a retail outlet. High compliance with access laws may consequently reduce the social as well as the commercial availability of cigarettes among youth. However, as an additional means of addressing the social availability of cigarettes, clinical, community, and school based interventions should try to dissuade minors who smoke from providing cigarettes to other minors.

YRBS data cannot be used to discern whether students who ask someone to buy their cigarettes, or borrow cigarettes from someone else, get their cigarettes from other minors or from people who may legally purchase tobacco. In a state wide California study, $11 \%$ of adults ( $\geqslant 18$ years) had been asked to 
provide tobacco to minors; smokers aged 18-19 years were the most likely to be asked (59\%), followed by $20-24$ year old smokers (39\%) and 18-24 year old non-smokers (38\%). ${ }^{42}$ Other studies suggest many adults are willing to buy cigarettes for minors. Klonoff and colleagues ${ }^{43}$ found that $32 \%$ of adults who were approached by youth and asked to purchase cigarettes did so. Similarly, Shive and colleagues ${ }^{44}$ found that $33 \%$ of college students were asked to provide tobacco to minors and of those approached, $31 \%$ did so. More research is needed to elicit detailed information on sources of borrowed cigarettes, the age and characteristics of the purchaser, and the extent to which minors are buying cigarettes for their peers.

We found that only a small percentage of current smokers rely mainly on stealing or vending machines to obtain their cigarettes ( $4 \%$ and $1 \%$, respectively). More research is needed to explore what students meant by stealing which may have included shoplifting and taking cigarettes from friends, family, or other smokers. Likewise, more research is needed to identify the extent to which current smokers used vending machines to supplement their usual source of cigarettes, or whether policy changes making vending machines less available, explains why vending machines are rarely a usual source for cigarettes.

This study is subject to several limitations. Firstly, the YRBS asked students about their "usual" source of cigarettes. These data cannot identify to what extent students used multiple sources to obtain their cigarettes. Nor does the YRBS ask students how easy it is for them to obtain cigarettes from any particular source. Secondly, the question addressing whether or not the student had been asked to show proof of age when buying cigarettes was restricted to students who were current smokers and who had bought cigarettes during the 30 days preceding the survey. Thus, it is not clear what proportion of students tried to buy cigarettes but were asked for proof of age and, because of their minority status, refused the sale. Thirdly, these data apply only to adolescents who attend high school and, therefore, are not representative of all adolescents. Still, in 1996, only $5 \%$ of persons aged 14-17 years were not enrolled in school..$^{45}$ Finally, these data are based on self reports. Although the survey questions have demonstrated good testretest reliability in a sample of high school students, ${ }^{46}$ students may under report or over report these behaviours.

\section{Conclusion}

To achieve reductions in tobacco related morbidity and mortality, reducing smoking among young people must be an element of a broader comprehensive tobacco use prevention effort. ${ }^{17}$ To try to reduce smoking initiation among young people, Congress enacted the Synar Amendment in 1992 to require every state to enact and enforce laws prohibiting the sale of tobacco to minors. ${ }^{11}{ }^{12}$ Synar state surveys over the past several years have found an overall decrease in the percentages of retailers who sell tobacco to minors ${ }^{47}$ YRBS data showed a decline in the percentage of high school students who usually bought their cigarettes in a store. It is not known to what extent enforcement of access laws has led to this reduction in retailers who sell to minors or to the shift in sources of cigarettes for minors. However, in spite of these laws, we found that one in four underage smokers rely most often on store purchases for their cigarettes. Furthermore, it remains that many minors appear to be able to buy cigarettes in a store without being asked for proof of age.

CDC has issued best practices guidelines for comprehensive tobacco control programmes that include strategies for enforcing restrictions on minors' access to tobacco. ${ }^{27}$ The agency recommends that states allocate $\$ 0.43$ to $\$ 0.80$ per capita for enforcing youth access regulations. Best practices recommend these per capita amounts need to be added to a base amount for interagency coordination of between $\$ 150000$ and \$300 000 .
Although reducing commercial access to cigarettes through the enactment and enforcement of tobacco access laws is important, the effectiveness of these laws may be undermined by social sources of cigarettes. Data from the Monitoring the Future study suggest only a slight decline from 1992 to 2000 in the percentage of 10th grade students (from 89\% to 87\%) who perceived it would be fairly easy or very easy to get cigarettes if they wanted some. ${ }^{18}$ Clearly, much more needs to be done to effectively reduce minors' overall access to tobacco. Research on effective interventions to reduce social sources is critical.

\section{Authors' affiliations}

S Everett Jones, L S Crossett, Division of Adolescent and School Health, National Center for Chronic Disease Prevention and Health Promotion (NCCDPHP), Centers for Disease Control and Prevention (CDC), Atlanta, Georgia, USA

D J Sharp, C G Husten, Office on Smoking and Health, NCCDPHP CDC, Atlanta

\section{REFERENCES}

1 US Department of Health and Human Services. Preventing tobacco use among young people. A report of the Surgeon General, 1994. Atlanta, Georgia: Public Health Service, Centers for Disease Control and Prevention, Office on Smoking and Health, 1994. (US Government Printing Office Publication No S/N 017-001-00491-0.)

2 Centers for Disease Control and Prevention. The great American smokeout - November 21, 1996. MMWR Morb Mortal Wkly Rep 1996:45:961.

3 Escobedo LG, Marcus SE, Holtzman D, et al. Sports participation, age at smoking initiation, and the risk of smoking among US high school students. JAMA 1993;269:1391-5

4 Taioli E, Wynder EL. Effect of the age at which smoking begins on frequency of smoking in adulthood. N Engl J Med 1991;325:968-9

5 Breslau N, Peterson EL. Smoking cessation in young adults: age at initiation of cigarette smoking and other suspected influences. Am J Public Health 1996;86:214-20.

6 Ershler J, Leventhal $\mathrm{H}$, Fleming $\mathrm{R}$, et al. The quitting experience for smokers in sixth through twelfth grades. Addict Behav 1989;14:365-78.

7 US Department of Health and Human Services. Reducing the health consequences of smoking: 25 years of progress. A report of the Surgeon General, 1989. Rockville, Maryland: Public Health Service, Centers for Disease Control, Office on Smoking and Health, 1989. (DHHS Publication No (CDC) 89-8411.)

8 Centers for Disease Control and Prevention. Projected smoking-related deaths among youth - United States. MMWR Morb Mortal Wkly Rep 1996;45:971-4.

9 US Department of Health and Human Services. Healthy People 2010. Conference Edition, in two nolumes. Washington, DC: US DHHS 2000.

10 Food and Drug Administration v. Brown \& Williamson Tobacco Corporation, 529 U.S. 120 (2000)

11 State Law Regarding Sale of Tobacco Products to Individuals Under Age of 18, 42 U.S.C. 300x-26 (1992).

12 Difranza JR. Are the federal and state governments complying with the Synar Amendment? Arch Pediatr Adolesc Med 1999;153:1089-97.

13 Altman DG, Wheelis AY, McFarlane M, et al. The relationship between tobacco access and use among adolescents: a four community study. Soc Sci Med 1999:48:759-75.

14 Rigotti NA, DiFranza JR, Chang Y, et al. The effect of enforcing tobacco-sales laws on adolescents' access to tobacco and smoking behavior. N Engl J Med 1997;337:1044-51.

15 Clark $\mathbf{P}$, Natanblut S, Schmitt CL, et al. Factors associated with tobacco sales to minors. JAMA 2000;284:729-34.

16 Forster J, Wolfson M. Youth access to tobacco: policies and politics. Annu Rev Public Health 1998;19:203-35.

17 Institute of Medicine, National Research Council. Taking action to reduce tobacco use. Washington DC: National Academy Press, 1998.

18 Johnston LD, O'Malley PM, Bachman JG. Cigarette use and smokeless tobacco use decline substantially among teens. University of Michigan News and Information Services, Ann Arbor, Mi. December 2000. Accessed October 15, 2001. URL: http://www.monitoringthefuture.org.

19 Centers for Disease Control and Prevention. Tobacco use and usual source of cigarettes among high school students - United States, 1995. MMWR Morb Mortal Wkly Rep 1996;45:413-18.

20 Centers for Disease Control and Prevention. Youth tobacco surveillance United States, 1998-1999. MMWR Morb Mortal Wkly Rep CDC Surveill Summ 2000:49(SS-10): 1-94.

21 Kann L, Warren CW, Harris WA, et al. Youth risk behavior surveillance - United States, 1995. MMWR Morb Mortal Wkly Rep CDC Surveill Summ 1996;45(SS-4): 1-86.

22 Kann L, Kinchen SA, Williams BI, et al. Youth risk behavior surveillance - United States, 1997. MMWR Morb Mortal Wkly Rep CDC Surveill Summ 1998;47(SS-3): 1-92. 
23 Kann L, Kinchen SA, Williams BI, et al. Youth risk behavior surveillance - United States, 1999. MMWR Morb Mortal Wkly Rep CDC Surveill Summ 2000;49(SS-5): 1-96.

24 Shah BV, Barnwell BG, Bieler GS. SUDAAN: Software for the statistical analysis of correlated data. User's Manual. 2nd ed. Research Triangle Park, North Carolina: Research Triangle Institute; 1996.

25 US Department of Health and Human Services. Reducing tobacco use: a report of the Surgeon General. Atlanta, Georgia: Centers for Disease Control and Prevention; 2000

26 Institute of Medicine. Growing up tobacco free: preventing nicotine addiction in children and youths. Washington DC: National Academy Press; 1994

27 Centers for Disease Control and Prevention. Best practices for comprehensive tobacco control programs - August 1999. Atlanta, Georgia: Centers for Disease Control and Prevention; 1999.

28 Cummings KM, Hyland A, Saunders-Martin T, et al. Evaluation of an enforcement program to reduce tobacco sales to minors. Am J Public Health 1998;88:932-6.

29 Gemson DH, Moats HL, Watkins BX, et al. Laying down the law: reducing illegal tobacco sales to minors in central Harlem. Am J Public Health 1998:88:936-9.

30 Jason L, Billows W, Schnopp-Wyatt D, et al. Reducing the illegal sales of cigarettes to minors: analysis of alternative enforcement schedules. J App Behav Anal 1996;29:333-44.

31 Levy DT, Chaloupka F, Slater S. Expert opinions on optimal enforcement of minimum purchase age laws for tobacco. J Public Health Manag Pract 2000;6: 107-14

32 Difranza JR, Celebucki CC, Seo HG. A model for the efficient and effective enforcement of tobacco sales laws. Am J Public Health 1998:88:1100-1.

33 Forster JL, Murray DM, Wolfson M, et al. The effects of community policies to reduce youth access to tobacco. Am J Public Health 1998;88: $1193-8$.

34 Biglan A, Ary DV, Smolkowski K, et al. A randomized controlled trial of a community intervention to prevent adolescent tobacco use. Tobacco Control 2000;9:24-32.
35 Jason LA, Billows WD, Schnopp-Wyatt DL, et al. Long-term findings from Woodbridge in reducing illegal cigarette sales to older minors. Eval Health Prof 1996;19:3-13

36 Landrine $\mathbf{H}$, Klonoff EA, Alcaraz R. Asking age and identification may decrease minors' access to tobacco. Prev Med 1996;25:301-6.

37 Forster JL, Wolfson M, Murray DM, et al. Perceived and measured availability of tobacco to youths in 14 Minnesota communities: the TPOP Study. Am J Prev Med 1997; 13:167-74.

38 Wolfson M, Forster JL, Claxton AJ, et al. Adolescent smokers' provision of tobacco to other adolescents. Am J Public Health 1997:87:649-51.

39 Post CM, Bell AJ, Finlan CA. Sources of cigarettes for high school students in two Ontario counties: implications for developing a community response. Can J Public Health 1999;90:395-6.

40 Cummings KM, Sciandra E, Pechacek TF, et al. Where teenagers get their cigarettes: a survey of the purchasing habits of 13-16 year olds in 12 US communities. Tobacco Control 1992;1:264-7.

41 Harrison PA, Fulkerson JA, Park E. The relative importance of social versus commercial sources in youth access to tobacco, alcohol, and othe drugs. Prev Med 2000;31:39-48.

42 RibisI KM, Norman GJ, Howard-Pitney B, et al. Which adults do underaged youth ask for cigarettes? Am J Public Health 1999;89:1561-4.

43 Klonoff EA, Landrine $H$, Lang $D$, et al. Adults buy cigarettes fo underaged youths. Am J Public Health 2001;91:1138-9.

44 Shive S, Ma GX, Shive E. A study of young adults who provide tobacco products to minors. J Sch Health 2001;71:218-22.

45 National Center for Educational Statistics. Digest of education statistics, 1997. Washington DC: Department of Education, 1997.

46 Brener ND, Collins JL, Kann L, et al. Reliability of the youth risk behavior survey questionnaire. Am J Epidemiol 1995;141:575-80.

47 The Substance Abuse and Mental Health Services Administration. Synar regulation: reducing youth access to tobacco (CSAP). Rockville, Maryland: Center for Substance Abuse Prevention, The Substance Abuse and Mental Health Services Administration. Accessed October 17 2001. URL: http://www.samhsa.gov/programs/content/brief2001/ 01 csapsynar.htm

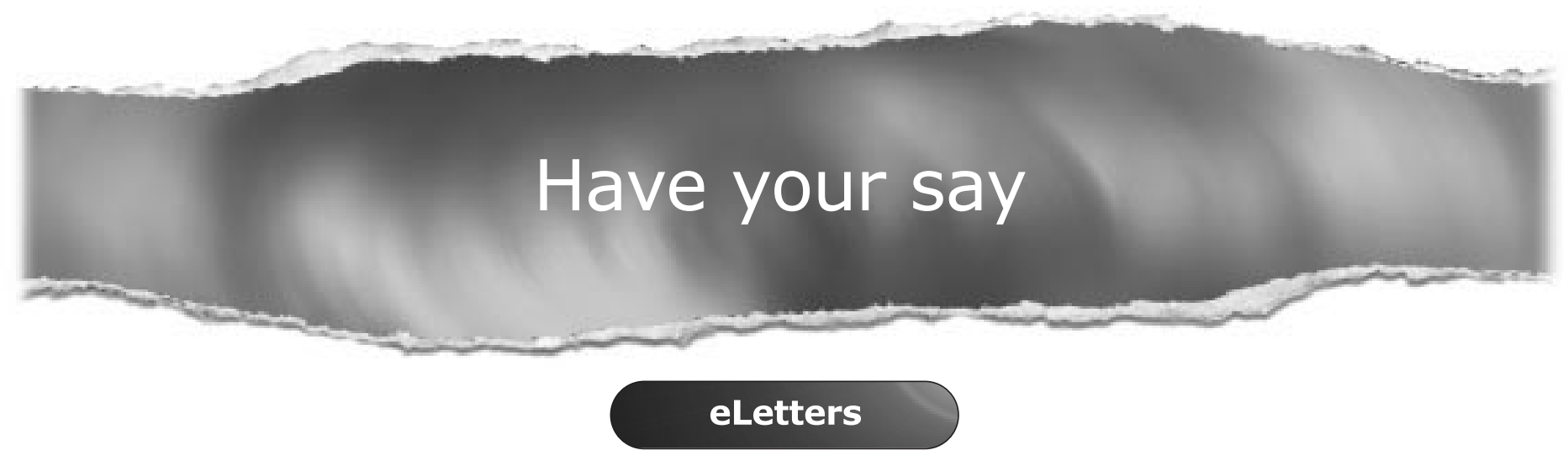

If you wish to comment on any article published in Tobacco Control you can send an eLetter using the eletters link at the beginning of each article. Your response will be posted on Tobacco Control online within a few days of receipt (subject to editorial screening).

\section{www.tobaccocontrol.com}

